\title{
Enhanced-efficiency fertilizers are not a panacea for resolving the nitrogen problem
}

Li, Tingyu; Zhang, Weifeng; Yin, Jiao; Chadwick, David; Norse, David; Lu, Yuelai; Liu, Xeujun; Chen, Xinping; Zhang, Fusuo; Powlson, David; Dou, Zhengxia

\section{Global Change Biology}

DOI:

$10.1111 / \mathrm{gcb} .13918$

Published: 01/02/2018

Peer reviewed version

Cyswllt i'r cyhoeddiad / Link to publication

Dyfyniad o'r fersiwn a gyhoeddwyd / Citation for published version (APA):

Li, T., Zhang, W., Yin, J., Chadwick, D., Norse, D., Lu, Y., Liu, X., Chen, X., Zhang, F., Powlson, D., \& Dou, Z. (2018). Enhanced-efficiency fertilizers are not a panacea for resolving the nitrogen problem. Global Change Biology, 24(2), e511-e521. https://doi.org/10.1111/gcb.13918

\footnotetext{
Hawliau Cyffredinol / General rights

Copyright and moral rights for the publications made accessible in the public portal are retained by the authors and/or other copyright owners and it is a condition of accessing publications that users recognise and abide by the legal requirements associated with these rights.

- Users may download and print one copy of any publication from the public portal for the purpose of private study or research.

- You may not further distribute the material or use it for any profit-making activity or commercial gain

- You may freely distribute the URL identifying the publication in the public portal ?
}

Take down policy

If you believe that this document breaches copyright please contact us providing details, and we will remove access to the work immediately and investigate your claim. 
PROF. ZHENGXIA DOU (Orcid ID : 0000-0001-9727-4750)

Article type : Primary Research Articles

\section{Enhanced-efficiency fertilizers are not a panacea for resolving the nitrogen problem}

Tingyu $\mathrm{Li}^{1 *}$, Weifeng Zhang ${ }^{1 *}$, Jiao Yin ${ }^{1}$, David Chadwick ${ }^{2}$, David Norse ${ }^{3}$, Yuelai $\mathrm{Lu}^{4}$, Xuejun Liu ${ }^{1}$, Xinping Chen ${ }^{1}$, Fusuo Zhang ${ }^{1}$, David Powlson ${ }^{5}$, and Zhengxia Dou ${ }^{6}$

${ }^{1}$ Key Laboratory of Plant-Soil Interactions, Ministry of Education, Center for Resources, Environment, and Food Security, China Agricultural University, Beijing 100193 China.

${ }^{2}$ School of Environment, Natural Resources and Geography, Bangor University, Bangor, Gwynedd, LL57 2UW, UK. ${ }^{3}$ Institute for Sustainable Resources, University College London, London WC1E 6BT, UK. ${ }^{4}$ School of International Development, University of East Anglia, Norwich NR4 7TJ, UK. ${ }^{5}$ Department of Sustainable Agriculture Sciences, Rothamsted Research, Harpenden AL5 2JQ, UK. ${ }^{6}$ Center for Animal Health and Productivity, School of Veterinary Medicine, University of Pennsylvania, Kennett Square, Pennsylvania 19348, USA.

*These authors contributed equally to this work.

This article has been accepted for publication and undergone full peer review but has not been through the copyediting, typesetting, pagination and proofreading process, which may lead to differences between this version and the Version of Record. Please cite this article as doi: $10.1111 /$ gcb. 13918

This article is protected by copyright. All rights reserved. 
Corresponding author: Zhengxia Dou

Email: douzheng@vet.upenn.edu

Tele: 6109256242

Fax: 6109256242

Running head: Using enhanced-efficiency fertilizers better

\begin{abstract}
Improving nitrogen $(\mathrm{N})$ management for greater agricultural output while minimizing unintended environmental consequences is critical in the endeavor of feeding the growing population sustainably amid climate change. Enhanced-efficiency fertilizers (EEFs) have been developed to better synchronize fertilizer $\mathbf{N}$ release with crop uptake, offering the potential for enhanced $\mathrm{N}$ use efficiency (NUE) and reduced losses. Can EEFs play a significant role in helping address the $\mathbf{N}$ management challenge? Here we present a comprehensive analysis of worldwide studies published in 1980-2016 evaluating four major types of EEFs (polymer-coated fertilizers PCF, nitrification inhibitors NI, urease inhibitors UI, and double inhibitors DI, i.e. urease and nitrification inhibitors combined) regarding their effectiveness in increasing yield and NUE and reducing $\mathbf{N}$ losses. Overall productivity and environmental efficacy depended on the combination of EEF type and cropping systems, further affected by biophysical conditions. Best scenarios include: (i) DI used in grassland (n=133), averaging $11 \%$ yield increase, $33 \%$ NUE improvement, and $47 \%$ decrease in aggregated $\mathrm{N}$ loss (sum of $\mathrm{NO}_{3}^{-}, \mathrm{NH}_{3}$, and $\mathrm{N}_{2} \mathrm{O}$, totaling $\left.84 \mathrm{~kg} \mathrm{~N} \mathrm{ha}^{-1}\right)$; (ii) UI in rice-paddy systems (n=100), with 9\% yield increase, $29 \% \mathrm{NUE}$ improvement, and $41 \% \mathrm{~N}$-loss reduction (16 $\mathrm{kg} \mathrm{N} \mathrm{ha}^{-1}$ ). EEF efficacies in wheat and maize systems were more complicated and generally less effective. In-depth analysis indicated that the potential benefits of EEFs might be best
\end{abstract}


achieved when a need is created, for example, by downward adjusting $\mathrm{N}$ application from conventional rate. We conclude that EEFs can play a significant role in sustainable agricultural production but their prudent use requires firstly eliminating any fertilizer mismanagement plus the implementation of knowledge-based $\mathrm{N}$ management practices.

Keywords: enhanced efficiency fertilizers; nitrous oxide emission, ammonia loss, nitrate leaching, biophysical conditions, nitrogen management

\section{Introduction}

Approximately $100 \mathrm{Tg}$ Haber-Bosch (synthetic) $\mathrm{N}$ is used in agricultural production on an annual basis, while only $17 \mathrm{Tg} \mathrm{N}$ is accounted for in human consumption of crops and animal food products (Erisman et al., 2008). A substantial fraction of the unaccounted-for reactive $\mathrm{N}(\mathrm{Nr})$ escapes into the environment, causing unwanted consequences (Erisman et al., 2008, Sutton et al., 2011b). Emissions of gaseous $\mathrm{N}$ compounds contribute to tropospheric pollution, decrease stratospheric ozone, and alter the balance of greenhouse gases (Sutton et al., 2011b). Nr losses to terrestrial, aquatic, and marine systems disrupt important ecosystem functions, resulting in adverse impact on human health (Sutton et al., 2013, Sutton et al., 2011a, Van Grinsven et al., 2013). In addition, the contribution of $\mathrm{Nr}$ to eutrophication of freshwater and coastal waters is particularly troubling around the world (Galloway et al., 2008). As the global food demand continues to soar and our reliance on synthetic $\mathrm{N}$ fertilizer for crop and livestock production persists, it is important to ask: What are our $\mathrm{N}$-management options for attaining greater productivity with less environmental damage?

Future research advancement may some day enable non-leguminous crops to fix their own $\mathrm{N}$ from the air (Beatty \& Good, 2011, Dent \& Cocking, 2017, Hopkin, 2006), therefore sparing their need for Haber-Bosch N. But the core strategy applicable here and now still resides in

This article is protected by copyright. All rights reserved. 
finding ways to improve $\mathrm{N}$ use efficiency (NUE, the fraction of $\mathrm{N}$ input captured in harvest) while reducing losses (Bodirsky et al., 2014, Erisman et al., 2008). (Supplemental measures such as altering human diets, reducing food waste, or enhancing the reuse of nutrients through recycling are other dimensions, beyond the scope of this study). One way to pursue greater NUE, long-advocated and management-driven, is the implementation of knowledge-based fertilizer use practices, which can be summarized by the $4 \mathrm{R}$ principle (Davidson et al., 2015; Flis, 2017) - right time (application), right amount (rate), right placement (e.g. incorporation below soil surface), and right product (e.g. urea, ammonia, or nitrate). Another approach that has attracted much attention is the development of enhanced efficiency N fertilizers (EEFs) (Smith et al., 2014, Smith et al., 2007). The key concept of EEFs is to slow the rate of $\mathrm{N}$ release from conventional fertilizers or delay $\mathrm{N}$ transformation processes by using inhibitors or coating materials to achieve a better synchronicity between $\mathrm{N}$ release and crop uptake, therefore reducing losses and enhancing NUE (Association of American Plant Food Control Officials, 1997). Since their inception in the 1960s, hundreds of EEF products have been developed. These products can be categorized into four major types: (i) urease inhibitors (UI), which delay urea hydrolysis thus lowering $\mathrm{NH}_{3}$ emission potential; (ii) nitrification inhibitors (NI), which reduce the activities of nitrifying bacteria therefore decreasing the risks of $\mathrm{NO}_{3}{ }^{-}$leaching as well as $\mathrm{N}_{2} \mathrm{O}$ emission; (iii) double inhibitors (DI), which are designed to lower $\mathrm{NH}_{3}$ emissions and $\mathrm{NO}_{3}{ }^{-}$and $\mathrm{N}_{2} \mathrm{O}$ losses by combining urease and nitrification inhibitors; and (iv) polymer-coated fertilizers (PCF), which use partially permeable coating material to control $\mathrm{N}$ release (Akiyama et al., 2009, Chien et al., 2009, Trenkel, 2010).

How effective are EEFs in improving productivity and environmental outcomes in the field? Could the technology provide a viable solution to help alleviate the $\mathrm{N}$ dilemma? Numerous studies have been conducted around the world. Most of them measured productivity indices (yield, NUE); many also monitored one or two N-loss parameters (mostly $\mathrm{N}_{2} \mathrm{O}$ emissions, sometimes $\mathrm{NH}_{3}$ volatilization or $\mathrm{NO}_{3}{ }^{-}$leaching loss). Results vary widely, showing different outcomes for different EEFs in different cropping systems or under different climate or soil conditions. Confounding factors make it difficult to attain a clear understanding 
about which EEF product may work where, and in what conditions. Recently, two groups of researchers used meta-analysis tools to synthesize results from a multitude of studies to explore the integrative efficacy of EEFs (Qiao et al., 2015, Xia et al., 2017). One of them focused on a single EEF type (NI); 62 worldwide studies were examined collectively (Qiao et al., 2015), showing a 9\% yield increase and $16.5 \% \mathrm{~N}$-loss reduction on average. The other analyzed the results of UI, NI, or PCF with studies originating from a single country - China (Xia et al., 2017); overall productivity and environmental outcomes were positive. Despite their detailed review and analysis, the global relevance of the conclusions from the two reports is limited because of the scope of the studies and/or geographic restrictions. To-date, after $>50$ years of research and development, there is still a lack of clear understanding regarding the effectiveness of EEFs in improving productivity and environmental performance and how different cropping systems respond to EEFs under varying biophysical conditions. In fact, there has been a rather broad misuse of EEFs in practice, at least regionally such as in China (see more in Discussion), indicating a 'blind' trust. An integrated and comprehensive assessment is urgently needed. Information derived from such an assessment would be useful for developing relevant policies as well as practical guidance. Such information would also provide the basis for a global perspective regarding EEFs' potential role in helping us deal with the $\mathrm{N}$ dilemma.

The present work aims at obtaining a global view on the productivity and N-loss reduction performance of EEFs through a holistic evaluation of all four EEF types in different cropping systems under wide ranging conditions. To attain this, a database was constructed from relevant research published between 1980-2016, totaling 203 studies from 18 countries. Subsequently, a meta-analysis was performed to explore the relative efficacies of NI, UI, DI, and PCF. We focused our analysis and interpretation on three key questions: (i) What is the effectiveness of EEFs in improving productivity (yield and NUE) and reducing $\mathrm{NH}_{3}, \mathrm{NO}_{3}{ }^{-}$, and $\mathrm{N}_{2} \mathrm{O}$ losses? (ii) How do cropping systems (grassland, rice-paddy, and dryland crops such as wheat and maize) and biophysical conditions (climate and soil conditions) interactively affect EEF efficacy? (iii) Under what scenarios can EEFs be used for the greatest potential benefit?

This article is protected by copyright. All rights reserved. 


\section{Materials and methods}

\section{Data acquisition}

We searched for peer-reviewed publications between 1980 and 2016 on efficacy of EEFs via the Web of Science and Google Scholar using search terms of enhanced-efficiency fertilizer, polymer coated fertilizer, urease inhibitor, nitrification inhibitor, yield, NUE, nitrous oxide, ammonia, and nitrate leaching. Key efficacy indicators included two production parameters (yield and NUE) and three forms of $\mathrm{N}$ losses $\left(\mathrm{N}_{2} \mathrm{O}\right.$ emission, $\mathrm{NH}_{3}$ volatilization, and $\mathrm{NO}_{3}{ }^{-}$ leaching). The $\mathrm{N}$-loss variables refer to cumulative $\mathrm{N}$ loss during a cropping cycle (from planting to harvest for cereal grains) or the entire growing season of a year (including multiple harvests of grass or vegetable crops). Yield refers to the economic yield of a given crop, as total dry matter for grass, corn silage, and grains; or market weight (wet) for vegetables. Nitrogen use efficiency refers to the proportion of applied $\mathrm{N}$ fertilizer assimilated in the above-ground or harvested parts (in the case of root crops), calculated by the N-difference method (above-ground or harvested crop N uptake in fertilized plots - crop $\mathrm{N}$ uptake in unfertilized plots)/rate of fertilizer $\mathrm{N}$ applied.

In addition to the prerequisite of one or more of the efficacy indicators being reported, studies selected also needed to conform to the following criteria: (i) Data must have originated from field experiments (i.e. laboratory-based studies were excluded), (ii) The experiments must have been replicated, (iii) Information needed to be provided regarding cropping systems, inhibitor type or the coating material of controlled release fertilizer, (iv) Management practices such as $\mathrm{N}$ fertilizer type, application rate, method, and placement, crop residue management (retention or removal), tillage, irrigation, and use of other agricultural chemicals had to be the same for the EEF treatment and control (i.e. conventional fertilizers). Where the same data appeared in multiple publications, it was entered into the meta-analysis database only once.

A total of 203 studies fit the criteria and were included in the meta-analysis, comprising over 140 experimental sites in 18 countries (Fig. S1). These included 72 studies for PCF, 105 for NI, 68 for UI, and 40 for DI (Table S1). NI, UI, and DI each had different chemical

This article is protected by copyright. All rights reserved. 
products in various studies (Table S2); for PCF, some studies specified the coating material (e.g. resin or polyolefin) but most studies simply reported as polymer coated fertilizers. Methods used for the determination of $\mathrm{N}$ losses are summarized in Table S3. The length of $\mathrm{N}$-loss monitoring period varied depending on the N-loss pathways and cropping systems. In most cases, $\mathrm{N}_{2} \mathrm{O}$ and $\mathrm{NH}_{3}$ emissions were recorded from planting to harvest for agronomic crops, whereas $\mathrm{NO}_{3}{ }^{-}$leaching was monitored for 300 days or year-round in grasslands.

\section{Meta-analysis}

From the selected studies, relevant data were extracted and entered into a meta-analysis database. Additional procedures were employed to facilitate subsequent analysis. Where data were presented in graphical forms, we digitized them using the software Getdata $2.0^{\mathrm{TM}}$ (GetData Pty Ltd, Kogarah NSW 2210, Australia). Annual average temperature and precipitation, if omitted in an original study, were obtained using the website of the World Meteorological Organization (www.wmo.int) for the area encompassing the experimental site. In a few cases where $\mathrm{N}$ losses were reported as hourly or daily flux, we totaled it to a cumulative $\mathrm{N}$ loss for the cropping cycle accordingly.

The efficacy of a given EEF type was assessed using the natural log of response ratio (RR) (Hedges et al., 1999), $\operatorname{lnRR}=\ln \left(x_{t} / x_{c}\right)=\ln \left(x_{t}\right)-\ln \left(x_{c}\right)$, where $x_{t}$ and $x_{c}$ are the means of EEF treatments and the control for a given indicator variable $\left(\mathrm{N}_{2} \mathrm{O}, \mathrm{NH}_{3}, \mathrm{NO}_{3}{ }^{-}\right.$, yield, or NUE). More than half of the datasets did not report standard error/deviation. To overcome this hurdle while maintaining a robust meta-analysis, we used the bootstrap resampling procedure (5000 iterations) to obtain the mean RR with a bias-corrected $95 \%$ confidence interval (CI) (Adams et al., 1997). The CIs obtained were wider than standard confidence limits, meaning that the resampling estimates are more conservative (Adams et al., 1997). An EEF treatment was considered significantly different from conventional fertilizers (i.e. the control) if the $95 \%$ CIs of RR did not include 1. 
In addition, we calculated the heterogeneity in lnRR between all studies (QT), within-group $(\mathrm{QW})$, and between-group (QB), where QT, QW and QB have chi-square distributions. A significant QB indicates that the RRs differ significantly for a given indicator variable in a particular category (e.g. annual rainfall, or SOC, etc.; Table S9). Sensitivity analysis was conducted to test the robustness of our meta-analysis. Outliers were identified by the boxplot with SPSS. An outlier is a data point that lies more than one and a half times the length of the box from either end of the box. Sensitivity analysis led to the identification of a small number of outliers, including five $\mathrm{N}_{2} \mathrm{O}$ data points each for PCF and UI, and one data point for $\mathrm{N}_{2} \mathrm{O}$ and $\mathrm{NH}_{3}$ each with NI treatment. Removing the outliers made little difference regarding the computed outcome (Table S10).

Experimental conditions e.g. land use/cropping systems and biophysical parameters e.g. climate and soil characteristics, can interactively affect the outcome of EEF treatments. To facilitate the identification of potential interactive effects, we grouped land use/cropping systems into grassland, dryland (wheat, maize, vegetables), and paddy systems. Detailed information on distribution of data points regarding cropping systems and EEFs is in Table S1. Other categorical groupings included: annual mean temperature $<10^{\circ} \mathrm{C}, 10-20^{\circ} \mathrm{C}$, $>20^{\circ} \mathrm{C}$; annual precipitation $<800 \mathrm{~mm}, 800-1200 \mathrm{~mm},>1200 \mathrm{~mm}$; water management (rainfed vs. irrigation); soil $\mathrm{pH}<6,6-8,>8$; soil organic carbon (SOC) $<10,10-40,>40 \mathrm{~g}$ $\mathrm{kg}^{-1}$; and soil texture classes coarse (sand, loamy sand, sandy loam, loam, silt loam, and silt), medium (sandy clay loam, clay loam, and silty clay loam), and fine (sandy clay, silty clay, and clay). Management factors, including $\mathrm{N}$ sources (synthetic vs. manure), $\mathrm{N}$ placement (surface vs. subsurface application), baseline $\mathrm{N}$ losses (from conventional plots), and crop rotation if any, were also noted.

The central focus of this meta-analysis was on the efficacy of EEFs concerning the two production variables and the three major $\mathrm{N}$ losses when experimentally tested in different cropping systems under various biophysical conditions. There can be additional effects associated with the use of EEFs, such as decreasing NO emission, increasing soil pH (Qiao et al., 2015), or reducing $\mathrm{N}$ runoff loss (Xia et al., 2017). Furthermore, different products within a given type of EEF may produce different outcomes. In addition, various This article is protected by copyright. All rights reserved. 
management alternatives, e.g. crop rotation vs. mono-cropping, surface vs. subsurface fertilizer placement, and inorganic vs. organic $\mathrm{N}$ sources, may interactively affect EEF efficacy. Those factors or effects are not included in the current meta-analysis, due primarily to limited observations and/or the impact being relatively minor or inconclusive.

\section{Results}

General description. The individual studies originated from all continents except Africa (Fig. S1). Of conventional $\mathrm{N}$ fertilizer treatments, urea dominated in the majority of the studies; the remaining were ammoniacal fertilizers in one form or another, in addition to organic $\mathrm{N}$ sources in a few cases. Taken together, there were more reported observations on productivity parameters (yield and NUE) than $\mathrm{N}$-loss measurements $\left(\mathrm{NH}_{3}, \mathrm{NO}_{3}{ }^{-}\right.$, or $\left.\mathrm{N}_{2} \mathrm{O}\right)$. Typically, $\mathrm{N}$ loss was determined in one or two forms, rarely all three forms, in individual studies. The number of reported N-loss observations tended to be the most numerous for $\mathrm{N}_{2} \mathrm{O}$ and the least for $\mathrm{NO}_{3}{ }^{-}$.

Grassland had the highest $\mathrm{N}$ loading intensity, with application rate averaging $472 \mathrm{~kg} \mathrm{~N} \mathrm{ha}^{-1}$ compared to 152 and $136 \mathrm{~kg} \mathrm{ha}^{-1}$ in dryland and paddy systems, and aggregated $\mathrm{N}$ loss (sum of $\mathrm{NH}_{3}, \mathrm{NO}_{3}^{-}$, and $\mathrm{N}_{2} \mathrm{O}$ ) averaging $178 \mathrm{~kg} \mathrm{ha}^{-1}$ compared to 70 and $39 \mathrm{~kg} \mathrm{ha}^{-1}$ (values are for the controls, i.e. with conventional fertilizer treatments), Table S4. In terms of quantity of N loss $\left(\mathrm{kg} \mathrm{N} \mathrm{ha}^{-1}\right)$, the dominating pathway was $\mathrm{NO}_{3}{ }^{-}$leaching in grassland and dryland, $\mathrm{NH}_{3}$ emission in paddy systems, whereas $\mathrm{N}_{2} \mathrm{O}$ emission was a magnitude smaller than $\mathrm{NO}_{3}{ }^{-}$or $\mathrm{NH}_{3}$ loss. Use of EEFs generally reduced losses of $\mathrm{NO}_{3}^{-}$(by 23-38 $\mathrm{kg} \mathrm{N}^{-1}$ on average), $\mathrm{NH}_{3}\left(20-27 \mathrm{~kg} \mathrm{~N} \mathrm{ha}^{-1}\right)$, and $\mathrm{N}_{2} \mathrm{O}\left(0.6-1.9 \mathrm{~kg} \mathrm{~N} \mathrm{ha}^{-1}\right)$, although not all decreases were significant. Tradeoffs existed for NI, with significantly increased $\mathrm{NH}_{3}$ volatilization but decreased $\mathrm{N}_{2} \mathrm{O}$ and $\mathrm{NO}_{3}{ }^{-}$losses. The impacts of EEFs on yield and NUE were generally positive in most cases but the extent of improvement was highly dependent on cropping systems and subject to biophysical conditions.

This article is protected by copyright. All rights reserved. 


\section{EEF efficacy in different cropping systems and biophysical conditions. Polymer-Coated}

Fertilizer The efficacy of PCF differed markedly between cropping systems (Fig. 1).

PCF appeared most effective in paddy systems, reducing $\mathrm{N}_{2} \mathrm{O}, \mathrm{NH}_{3}$, and $\mathrm{NO}_{3}{ }^{-}$losses by 74 , 83, and $92 \%$ on average (Fig. 1a; Tables S5), despite the relatively small number of observations particularly for $\mathrm{NO}_{3}{ }^{-}(\mathrm{n}=3)$. For grasslands, only three sets of data were available, showing a $74 \%$ reduction in $\mathrm{N}_{2} \mathrm{O}$ (with a very large variation) and $\mathrm{NH}_{3}$ losses; there were no data on $\mathrm{NO}_{3}{ }^{-}$leaching loss. When used in dryland systems, $\mathrm{PCF}$ was much less effective compared to the other cropping systems, with reductions of various $\mathrm{N}$ losses ranging from 23 to $42 \%$ (Fig. 1a). Climate and soil conditions affected PCF efficacy (Tables S5, S9). In particular, $\mathrm{PCF}$ was more effective in reducing $\mathrm{N}_{2} \mathrm{O}$ and $\mathrm{NH}_{3}$ losses in irrigated than rainfed systems as well as in soils of coarse texture or low organic carbon content ( $\mathrm{SOC}<10 \mathrm{~g} \mathrm{~kg}^{-1}$ ) compared to other soils (Figs. S2, S3).

Yield and NUE responses to PCF were positive in rice-paddy systems (5\% and 26\%) as well as vegetable production systems (7\% and 11\%). However, PCF had little impact on wheat or maize yield or NUE, while in grasslands PCF tended to decrease yield and NUE (Fig. 1b). Where temperature and rainfall were favorable for growth $\left(10-20^{\circ} \mathrm{C}\right.$ and $\left.800-1200 \mathrm{~mm}\right), \mathrm{PCF}$ boosted yield by $4-7 \%$ and NUE by $14-15 \%$; under other climate conditions, PCF showed no effect (Fig. S4). The positive effects on yield and NUE were shown in irrigated system but not in rainfed system (Fig. S5) Also, in acidic or alkaline soils ( $\mathrm{pH}<6$ or $>8$ ), the effect of PCF on enhancing NUE tended to diminish compared to more neutral $\mathrm{pH}$ soils (Table S5).

When originally developed, PCF was intended for use on golf courses, home lawns, landscaping and garden nurseries (Trenkel, 1997), for which controlled $\mathrm{N}$ release serves the purpose of prolonging the greenness of vegetation, but where biomass production is of little interest. PCF products subsequently developed for grassland or dryland crops such as wheat and maize do not appear to have $\mathrm{N}$ release patterns that align with $\mathrm{N}$ demand, leading to the lack of yield and NUE response in these cropping systems. In contrast, the positive effects measured in paddy and vegetable systems were probably due to specific biophysical conditions (including more constant temperature and water availability) conducive to $\mathrm{N}$ release and uptake. Nitrogen release from PCF involves water penetrating the 
semipermeable membrane coating, dissolving and releasing N (Shaviv, 2005). The absence of yield and NUE responses to PCF in grassland and dryland crops raises a question: What is the fate of $\mathrm{N}$ that is apparently "saved" from losses, totaling $124 \mathrm{~kg} \mathrm{ha}^{-1}$ in grassland and 63 $\mathrm{kg} \mathrm{ha}^{-1}$ in the wheat and maize systems (Table S11), if not captured by the growing plants? We hypothesize that some of the $\mathrm{N}$ may still be in the coated material, therefore protected, which would be subject to potential losses if released late in the season after $\mathrm{N}$ uptake slows or ceases. Post-season losses might not have been accounted for in the original field studies since field-monitoring activities were typically terminated around harvest, particularly for agronomic crops. Further research is needed to fill this information gap.

Nitrification Inhibitors NI affected N losses in a similar pattern across all cropping systems (Fig. 2a), reducing $\mathrm{NO}_{3}{ }^{-}$leaching loss by $35 \%$ to $52 \%$ with the number of observations ranging from many for grasslands $(n=59)$ to only a few for paddy systems $(n=2)$. Reduction in $\mathrm{N}_{2} \mathrm{O}$ emissions ranged from $33 \%$ to $58 \%$ for the three cropping systems (Table S6). Interestingly, the higher the baseline $\mathrm{N}_{2} \mathrm{O}$ emission (i.e. emissions from the conventional fertilizer treatments), the greater the reduction in $\mathrm{N}_{2} \mathrm{O}$ loss by NI (Fig. 2a). For example, the average $\mathrm{N}_{2} \mathrm{O}$ reduction was $67 \%$ for situations where baseline emissions exceeded $20 \mathrm{~kg} \mathrm{~N} \mathrm{ha}^{-1}$, compared to a $50 \%$ reduction for baseline emissions of $<1 \mathrm{~kg} \mathrm{~N} \mathrm{ha}^{-1}$. Climate or soil conditions did not affect NI efficacy in reducing $\mathrm{NO}_{3}{ }^{-}$leaching. NI was more effective in reducing $\mathrm{N}_{2} \mathrm{O}$ emissions in fine-textured soils (77\% reduction, compared to $59 \%$ or $44 \%$ in coarse or medium-textured soils), acidic soils (64\% reduction for soils of $\mathrm{pH}<6$, compared to $48 \%$ or $41 \%$ for soil $\mathrm{pH}$ 6-8 or $>8$ ), and soils with intermediate SOC (63\% reduction for SOC $10-40 \mathrm{~g} \mathrm{~kg}^{-1}$, compared to $32 \%$ and $50 \%$ for soils with lower or higher SOC) (see Fig. S6 for details). NI had similar impact on N loss mitigation regardless of irrigation or rainfed systems (Fig. S7).

The tradeoff of NI in increasing $\mathrm{NH}_{3}$ emission, as reported previously (Qiao et al., 2015, Xia et al., 2017), was present for all cropping systems and varied from a low of $13 \%$ in grassland to a high of $28 \%$ in dryland systems (Fig. 2a). The net result, in terms of aggregated N-loss reduction, was 52,6 , and $7 \mathrm{~kg} \mathrm{ha}^{-1}$ for grassland, dryland, and paddy systems (Table S11). In other words, the tradeoff greatly diminished the overall effect on N-loss reduction,

This article is protected by copyright. All rights reserved. 
particularly when NI was used in the dryland or paddy systems. This also means that the "climate benefit" of NI in decreasing direct $\mathrm{N}_{2} \mathrm{O}$ emissions is partially offset by increased indirection emissions. It is worth noting that in alkaline soils $(\mathrm{pH}>8)$, NI did not further increase $\mathrm{NH}_{3}$ emission compared to the control (Table S6). Whether this is due to inherently high $\mathrm{NH}_{3}$ losses in such soils (baseline $\mathrm{NH}_{3}$ emission might be maximized in high-pH soils), or the possibility of NI losing its potency in alkaline soils (Rodgers et al., 1985), remains unclear.

Crops responded to NI differently (Fig. 2b). There was little response by vegetables, marginal response by wheat and maize, but a modest response in paddy systems (6\% yield increase and 11\% NUE improvement). For grassland, there was a yield increase of $7 \%$ with a large improvement in NUE (48\%). Lower annual average temperature appeared to enhance the impact of NI on increasing NUE, $30 \%$ higher in areas of $<10^{\circ} \mathrm{C}$, compared to $12 \%$ otherwise, possibly due to slower degradation of NI and thus an extended effect (Prasad \& Power, 1995). The positive effects of NI on yield and/or NUE tended to diminish in areas of high rainfall (>1200 mm) or soils with high $\mathrm{pH}(>8)$ (Fig. S8, S9). Furthermore, NI was apparently more effective in enhancing NUE in irrigated compared to rainfed systems (Fig. S10).

Urease Inhibitors UI reduced $\mathrm{NH}_{3}$ volatilization by about $60 \%$ in all cropping systems, amounting to 31,20 , and $16 \mathrm{~kg} \mathrm{~N} \mathrm{ha}^{-1}$ for grassland, dryland, and paddy systems, compared to the control (Tables S7, S11). The higher the baseline $\mathrm{NH}_{3}$ emission, the greater the reduction by UI (Fig. 3a). Dry areas (annual rainfall $<800 \mathrm{~mm}$ ) benefitted more from UI treatment, with $70 \%$ reduction in $\mathrm{NH}_{3}$ emission, compared to $50 \%$ reduction in high-rainfall areas (Fig. S11). This is consistent with the aggregated results showing more effective of UI on reducing $\mathrm{NH}_{3}$ losses in rainfed than in irrigated systems (Fig. S12). Also, there was a greater reduction in $\mathrm{NH}_{3}$ emission by UI in soils of higher $\mathrm{pH}$ or coarser texture than other soils (Fig. S13). There remains a marked data gap regarding the potential impacts of UI on $\mathrm{NO}_{3}{ }^{-}$leaching loss (Fig. 3a). Additional research is also needed to further clarify or validate the effect of UI on $\mathrm{N}_{2} \mathrm{O}$ emission. Nevertheless, the net impact of UI is likely to be a 
decrease in aggregated $\mathrm{N}$ loss, considering that the reduction of $\mathrm{NH}_{4}{ }^{+}$in soil (from the urease inhibition) would mean less $\mathrm{NO}_{3}{ }^{-}$for potential leaching as well as for denitrification.

Yield response to UI was positive in grassland and dryland systems (3-5\% increases), and more notable in paddy systems (a 9\% increase). Enhancement in NUE ranged from 14 to 29\% (Fig. 3b). The generally positive responses in yield and NUE across all cropping systems suggest that the use of UI likely resulted in a net reduction in $\mathrm{N}$ losses, despite the lack of data for $\mathrm{NO}_{3}{ }^{-}$leaching. There was little indication of interactive climate and soil effects on yield or NUE except that warmer areas with irrigation tended to have greater yield and NUE with UI treatments than otherwise (Figs. S14, S15).

Double Inhibitors In grasslands, DI reduced all three forms of N losses, ranging from 37 to $51 \%$ (Fig. 4a; Table S8); aggregated N-loss reduction amounted to $84 \mathrm{~kg} \mathrm{ha}^{-1}$. Meanwhile, grassland responded to DI favorably, with an increase of $11 \%$ in yield and $33 \%$ in NUE (Fig. 4b). For paddy systems, there were only six observations for $\mathrm{NH}_{3}$ and seven for yield or NUE (Fig. 4), showing an average $76 \%$ reduction in $\mathrm{NH}_{3}$ emission and $4 \%$ increase in yield with an enhanced NUE of 43\%. In dryland systems, DI lowered $\mathrm{N}_{2} \mathrm{O}$ and $\mathrm{NH}_{3}$ emissions by $54 \%$ and $70 \%$ but increased $\mathrm{NO}_{3}{ }^{-}$leaching by $58 \%$ (Fig. 4a). It is not clear why DI, containing both urease and nitrification inhibitors, would increase $\mathrm{NO}_{3}{ }^{-}$leaching loss (note the small number of observations, $n=5$ ). Nevertheless, there is solid evidence that DI was ineffective in enhancing yield or NUE of the dryland crops, backed by a large number of observations ( $\mathrm{n}=59$ for yield and 16 for NUE; Fig. 4b).

Climate and soil conditions had considerable impact on DI efficacy. There was no improvement in yield or NUE with DI treatments in areas with rainfall $<800 \mathrm{~mm}$, but significant positive responses $(11 \%$ and $30 \%$ increases in yield and NUE; $n=27$ including all three cropping systems) in areas with rainfall between 800 and $1200 \mathrm{~mm}$ (Fig. S16). Consistently, irrigated fields benefitted more from DI treatment than rainfed systems, with greater yield and NUE and reduced N losses (Fig. S17, S18). DI applied to coarse-textured or acidic soils tended to have more positive responses than other soils (Fig. S19, S20).

This article is protected by copyright. All rights reserved. 
Interpretative summary. Clearly, one EEF product does not fit all systems. Taking both productivity and environmental impacts into consideration, we derived the following inferences regarding which product might be best suited for what cropping systems based on the experimental results derived from the meta-analysis. The best EEF treatment for a given cropping system should have the greatest potential on enhancing productivity (yield and NUE) while reducing aggregated $\mathrm{N}$ loss. For grassland, the ranking is $\mathrm{DI}>\mathrm{NI}>\mathrm{UI}$ for yield increases, NI $>$ DI $>$ UI for NUE improvement, and $\mathrm{PCF}>\mathrm{DI}>\mathrm{NI}>\mathrm{UI}$ for $\mathrm{N}-$ loss reduction (Fig. 5a). Taken together, DI would be the preference, increasing yield by $11 \%$ and NUE by $33 \%$ while decreasing aggregated $\mathrm{N}$ loss by $47 \%\left(84 \mathrm{~kg} \mathrm{~N} \mathrm{ha}^{-1}\right)$, the positive effects were shown under all soil and climate conditions tested (Table S12). NI is also a viable option with a yield increase of $7 \%$, NUE improvement of $48 \%$, and aggregated N-loss reduction of $29 \%(52 \mathrm{~kg}$ $\mathrm{ha}^{-1}$ ) across all conditions tested, although it is more effective in improving productivity in coarse- than medium-textured soils and less effective where annual rainfall exceeds $1200 \mathrm{~mm}$ (Table S12). UI offers both productivity and N-loss reduction benefits but to a lesser extent compared to DI or NI. The negative impact of PCF on productivity plus the uncertainty associated with the "saved N" as mentioned earlier undermines its value for the grassland system. For paddy systems, the ranking is $\mathrm{UI}>\mathrm{NI}>\mathrm{PCF}>\mathrm{DI}$ for yield increases, $\mathrm{DI}>\mathrm{UI}>\mathrm{PCF}>\mathrm{NI}$ for NUE improvement, and $\mathrm{PCF}>\mathrm{DI}>\mathrm{UI}>\mathrm{NI}$ for $\mathrm{N}-$ loss reduction (Fig. $5 \mathrm{c}$ ). Taken together, UI would be the best option with the greatest yield increase (9\%) plus NUE improvement of $29 \%$, and an aggregated $\mathrm{N}-$ loss reduction of $41 \%\left(16 \mathrm{~kg} \mathrm{~N} \mathrm{ha}^{-1}\right)$. The efficacy of UI on enhancing productivity is consistent under different soil and climate conditions, although it appears to be more effective on neutral to alkaline as well as coarse-textured soils (Table S12). The other three EEF types are all effective in providing environmental and productivity benefits albeit to a lesser extent than UI in one parameter or another (Fig. 5c).

For wheat and maize systems, the overall effects of EEFs on productivity enhancement and $\mathrm{N}$-loss reduction are less substantial than the other two cropping systems as discussed above. Comparatively speaking, UI offers a small yield increase (3\%) along with NUE improvement (14\%) and $\mathrm{N}-$-loss reduction $\left(28 \%\right.$, or $\left.20 \mathrm{~kg} \mathrm{~N} \mathrm{ha}^{-1}\right)$; UI tends to be more effective in 
improving yield and NUE on alkaline soils or irrigated fields but ineffective where annual average temperature is below 10 (Table S12). NI can also be an option with comparable benefits in improving productivity but rather marginal reduction in aggregated $\mathrm{N}$-loss; the latter is due to the tradeoff of increased $\mathrm{NH}_{3}$ emissions as discussed earlier (consistent under all soil, climate, and water management conditions tested). DI is ineffective except for a marginal yield increase (less than 3\%). PCF offers little or even negative effect on productivity (Fig. 5b), despite a minor positive effect on productivity in irrigated systems (Figs. S3, S5). Furthermore, the fate of the apparently "saved" N with PCF treatment needs further investigation as mentioned earlier.

Compared to rice-paddy systems or grasslands, the wheat and maize systems were least responsive to EEFs (Fig. 5). Pooling studies across all EEF types together, we found that wheat and maize had an average yield increase of $1.3 \%(n=324)$ and NUE improvement of $1.8 \%(n=111)$ with EEF treatments compared to the controls, while rice yield increased by $5.8 \%(\mathrm{n}=145)$ and NUE improved by $27.8 \%(\mathrm{n}=78)$ (Table S13). We reason that dryland systems such as wheat and maize are generally subject to variation and fluctuation of biophysical conditions such as temperature and soil moisture, to a greater extent than paddy systems, for a given site or across multiple sites. Such fluctuations in dryland systems would affect N-release patterns from EEFs, and possibly the dynamics of crop growth and $\mathrm{N}$ uptake. In other words, the inherent differences in micro- i.e. field-scale biophysical conditions may afford better synchronicity of $\mathrm{N}$ release and uptake in paddy systems but render EEFs less effective for dryland crops. As for grassland, the generally greater efficacy of EEFs, compared to dryland crops, probably derives from grass's dense roots capturing $\mathrm{N}$ more efficiently than the row crops of wheat and maize with their shallower roots particularly in the early growth stage.

This article is protected by copyright. All rights reserved. 


\section{Discussion}

EEFs cost 1.3-1.6 times more than conventional fertilizers (Trenkel, 2010). For farmers, what would be the economic outcome of using EEFs vs. conventional fertilizers? Assuming a cost factor of 1.45 for EEFs and using available information on grain prices, rate and cost of N fertilizers (Table S14), we calculated the breakeven yield increase (BYI) to be 195, 102, and $87 \mathrm{~kg} \mathrm{ha}^{-1}$ for maize, wheat, and rice, respectively. Comparatively, average yield increases in our database were 160,100 , and $410 \mathrm{~kg} \mathrm{ha}^{-1}$ for maize, wheat, and rice, respectively. Accordingly, a net profit is expected for paddy systems only, whereas use of EEFs in wheat or maize would bring little financial gains to farmers. Reducing the cost of EEFs (via subsidies, for instance) or higher grain prices would lower the BYI, consequently changing the cost-benefit outcome. Needless to say, opportunity cost (Xia et al., 2017), farmers' risk-averse nature, and other socioeconomic factors would further complicate the matter, detailed discussion of which is beyond the scope of the present work.

Notably, the cost-benefit situation would differ substantially when environmental outcomes are considered, e.g. the consequences of $\mathrm{NO}_{3}{ }^{-}$contaminating drinking water supplies or $\mathrm{NH}_{3}$ affecting air quality and human health, and the global warming effect of $\mathrm{N}_{2} \mathrm{O}$ - these and other externality costs associated with $\mathrm{N}$ losses can be huge. On this basis, targeted subsidies for EEFs could be environmentally cost-effective. For example, a decrease in $\mathrm{N}_{2} \mathrm{O}$ emission of $1 \mathrm{~kg} \mathrm{~N} \mathrm{ha}^{-1}$ (equal to $1.57 \mathrm{~kg} \mathrm{~N}_{2} \mathrm{O} \mathrm{ha}^{-1}$ ) translates to $471 \mathrm{~kg} \mathrm{CO}_{2}$-equivalent ha ${ }^{-1}$ (or $129 \mathrm{~kg} \mathrm{C} \mathrm{ha}^{-1}$ ) taking account of the fact that $\mathrm{N}_{2} \mathrm{O}$ is approximately 300 more powerful as a greenhouse gas than $\mathrm{CO}_{2}$. Therefore, in terms of national efforts to decrease greenhouse gas emissions, targeted subsidies of NIs or UIs in specific situations may be useful. However, we caution that subsidy policies must be carefully designed to avoid sending the “wrong message”, especially where poor fertilizer management prevails, such as China. Based on our research experience as well as field observations, there is a common misconception even among many in the agricultural research communities that EEFs can help resolve the $\mathrm{N}$ loss dilemma, with little regard on how $\mathrm{N}$ fertilizers are used. The seemingly 'blind' trust has an unwanted consequence of making poor fertilizer management practices excusable. In fact, of the 203 studies tallied in our meta-analysis, about $70 \%$ used EEFs This article is protected by copyright. All rights reserved. 
(along with conventional fertilizers in the control treatments) as surface rather than subsurface application. This is an indication of possibly widespread (global) practice of surface applying $\mathrm{N}$, instead of subsurface incorporation for better NUE and less $\mathrm{N}$ losses. The core message is, EEFs are not a panacea for addressing the $\mathrm{Nr}$ challenge without the elimination of fertilizer mismanagement and the implementation of knowledge-based management practices.

Conceivably, if the delayed $\mathrm{N}$ release from EEFs is not captured by crops, it would be subject to losses. Therefore, a net increase in $\mathrm{N}$ uptake is expected if there is a recorded net reduction in $\mathrm{N}$ loss with EEF treatment, unless the "saved" $\mathrm{N}$ is retained in soil in one form or another. Close examination of the data did reveal a general co-occurrence of a net increase in $\mathrm{N}$ uptake with a net reduction in $\mathrm{N}$ losses in EEF treatments compared to controls (Fig. S21; Table S15), although their quantities differ and deviate from a 1:1 ratio. PCF did not follow this pattern, particularly in grassland and dryland systems (Table S15); the possibility of the apparently "saved" $\mathrm{N}$ remaining in the coated/protected materials needs to be investigated, as mentioned earlier. Also, there is a strong correlation between aggregated $\mathrm{N}$-loss reduction and NUE in the various EEF-cropping system combinations $\left(\mathrm{R}^{2}=0.4\right.$ for all nine data points; $\mathrm{R}^{2}=0.9$ if one data point is excluded as an outlier; PCF is not included in the analyses; Fig. S21). This can serve as indirect evidence to further support the above reasoning. From the in-depth examination of the data, we conclude that the ultimate effectiveness of EEFs is determined not only by its technologically-designed ability to modify N-release patterns but also, and equally importantly, by whether or not the released $\mathrm{N}$ can be captured by crops. The latter will depend on the overall $\mathrm{N}$ supply-demand dynamics, among other things. If $\mathrm{N}$ supply adequately meets crop needs, i.e. $\mathrm{N}$ is not the growth-limiting factor, there would be little chance for the EEF-associated $\mathrm{N}$ to translate to greater productivity. This is the essence, we argue, concerning how EEFs may be best utilized to mitigate the $\mathrm{N}$ problem under different situations around the world, as discussed below.

This article is protected by copyright. All rights reserved. 
The $\mathrm{N}$ dilemma manifests in different contexts around the globe. This can be comparatively analyzed in three distinct scenarios (Vitousek et al., 2009) (Fig. 6): (i) $\mathrm{N}$ deficiency in areas such as Sub-Saharan Africa, where low fertilizer inputs severely limit yield while depleting the soil reserves; (ii) $\mathrm{N}$ surplus in regions like China, where over application and mismanagement of $\mathrm{N}$ fertilizers result in poor NUE with widespread pollution problems; (iii) $\mathrm{N}$ more-or-less balanced in many developed regions such as North America, where implementation of knowledge-based management practices aims at maintaining an adequate $\mathrm{N}$ supply for high yield while minimizing excessive $\mathrm{N}$ in the soil-crop system and subsequent environmental losses. Given the N-status disparity, how can EEFs be used sensibly and realistically to attain their environmental and productivity potential? We propose the following principal guidelines, which may serve as discussion points moving forward.

For areas such as Sub-Saharan Africa with extremely low $\mathrm{N}$ input (less than $10 \mathrm{~kg} \mathrm{~N} \mathrm{ha}^{-1}$ ) (FAO, 2016) and high NUE (0.72; Zhang et al., 2015), use of EEFs is not a priority. It is also impractical economically considering the extra cost for EEFs. What these areas need urgently is greater availability and application of fertilizers, at affordable cost, along with other measures such as integrated crop and livestock management, to boost yield while restoring soil fertility. At the other end of the spectrum, with widespread mismanagement of $\mathrm{N}$ fertilizers and NUE extremely low, for example, 0.25 in China and 0.30 in India (Zhang et al., 2015), relying on EEFs without correcting the current $\mathrm{N}$ misuse would be meaningless environmentally, agronomically, and economically. Here, eliminating $\mathrm{N}$ over-application should be the first step prior to considering the use of EEFs. As demonstrated repeatedly at regional and national scales in China, $\mathrm{N}$ fertilizer rates could be cut almost in half without loss of yield or grain quality, and in the process reducing $\mathrm{N}$ losses by $>50 \%$ (Ju et al., 2009, Zhang et al., 2012). Furthermore, implementation of knowledge-based $\mathrm{N}$ management practices, such as split (multiple) applications, subsurface placement, or $\mathrm{N}$ rate formulated according to soil test results, is also important and effective for the very purpose of improving NUE and reducing $\mathrm{N}$ losses (Xia et al., 2017). We urge researchers to couple EEF treatments with knowledge-based management practices in future studies, as the majority of previous studies failed to address this important matter. We believe that only by using $\mathrm{N}$

This article is protected by copyright. All rights reserved. 
fertilizers prudently, i.e. eliminating misuse and implementing time-honored and widely-accepted management practices could the adoption of EEFs bring forth their greatest benefits (Fig. 6).

For areas such as North America where $\mathrm{N}$ inputs are approximately in balance with crop demand, use of EEFs may help further enhance NUE (currently 0.68 in the U.S., for example; Zhang et al., 2015) and lower $\mathrm{N}$ losses. In this situation, we argue that adjusting conventional $\mathrm{N}$ application rates downwards to somewhat below optimum $\mathrm{N}$ level may create the opportunity to best utilize the potential benefits afforded by EEFs. The logic behind this notion is: the $\mathrm{N}$ "saved" from losses by EEFs may not translate to greater crop productivity unless there is an N-supply shortfall, as discussed earlier. To further illustrate this concept, we examined the database and identified studies that included a "High" and a "Low" N rate with EEF treatments. "High" refers to the conventional $\mathrm{N}$ rate (N supply presumably near or above optimum); "Low" is 50-70\% of the conventional rate ( $\mathrm{N}$ supply somewhere below optimum). Not surprisingly, the Low group showed an average yield increase of $8.2 \%$ with EEF treatments, compared to $3.6 \%$ for the High group (Table S16); likewise, NUE improvement was $16.1 \%$ in the Low group, compared to $3.7 \%$ for the High group. The same pattern applies when the combinations of EEFs-cropping systems are examined separately (Table S17). Notably, the need to lower conventional N rates when coupled with EEFs has been recognized by some researchers (those who included a Low rate); still, the majority of the studies in our database were conducted with a single (conventional) $\mathrm{N}$ rate. In the latter situation, an increase in $\mathrm{N}$ supply to crop (through decreased $\mathrm{N}$ loss caused by an EEF) will produce little or no yield increase because the curve of yield versus $\mathrm{N}$ applied is at a plateau. Indeed, an increase in NUE not accompanied by increased crop yield, as observed in many cases, is a strong indication of this phenomenon, often termed "luxury uptake" of N. More research is needed to test this concept and to determine EEF-adjusted fertilization rates for different cropping systems.

To summarize, EEFs can help attain greater productivity while reducing environmental $\mathrm{N}$ loss when the right type of product is used in the right cropping system under the right biophysical conditions. The greatest opportunity resides in situations where the adoption of This article is protected by copyright. All rights reserved. 
EEFs is coupled with the implementation of knowledge-based management practices, with conventional $\mathrm{N}$ rate adjusted to enable the "saved" $\mathrm{N}$ to translate into enhanced productivity. Any notion of relying on EEFs alone to solve the $\mathrm{N}$ dilemma, without seriously tackling existing problems of $\mathrm{N}$ fertilizer mismanagement, would be unfounded.

\section{Acknowledgements}

This work was supported by National Key Technologies R\&D Program (Grant 2016YFD0201303), National Basic Research Program of China, 973 Program (Grant 2015CB150405), National Natural Science Foundation of China (Grants 31421092 and 41425007), and Department of Agriculture Project (Grant 101721301122441007). It was also the result of the UK-China Virtual Joint Centre for Agricultural Nitrogen (CINAg, BB/N013468/1), which is jointly supported by the Newton Fund, via UK BBSRC and NERC, and the Chinese Ministry of Science and Technology, and the UK-China Sustainable Agriculture Innovation Network (SAIN).

\section{References}

Adams DC, Gurevitch J, Rosenberg MS (1997) Resampling tests for meta-analysis of ecological data. Ecology, 78, 1277-1283.

Akiyama H, Yan X, Yagi K (2009) Evaluation of effectiveness of enhanced-efficiency fertilizers as mitigation options for $\mathrm{N}_{2} \mathrm{O}$ and $\mathrm{NO}$ emissions from agricultural soils: meta-analysis. Global Change Biology, 16, 1837-1846.

Beatty PH, Good AG (2011) Future Prospects for Cereals That Fix Nitrogen. Science, 333, 416-417.

Bodirsky BL, Popp A, Lotze-Campen H et al. (2014) Reactive nitrogen requirements to feed the world in 2050 and potential to mitigate nitrogen pollution. Nature Communications, 5, 3858.

This article is protected by copyright. All rights reserved. 
Chien S, Prochnow L, Cantarella H (2009) Recent developments of fertilizer production and use to improve nutrient efficiency and minimize environmental impacts. Advances in agronomy, 102, 267-322.

Davidson EA, Suddick EC, Rice CW, Prokopy LS (2015) More Food, Low Pollution (Mo Fo Lo Po): A Grand Challenge for the 21st Century. Journal of Environmental Quality, 44, 305-311.

Dent D, Cocking E (2017) Establishing symbiotic nitrogen fixation in cereals and other non-legume crops: The Greener Nitrogen Revolution. Agriculture \& Food Security, 6, 7.

Erisman JW, Sutton MA, Galloway J, Klimont Z, Winiwarter W (2008) How a century of ammonia synthesis changed the world. Nature Geoscience, 1, 636-639.

Flis S (2017) The 4Rs in crop nitrogen research. Crops and Soils, 50, 18-20.

Galloway JN, Townsend AR, Erisman JW et al. (2008) Transformation of the nitrogen cycle: Recent trends, questions, and potential solutions. Science, 320, 889-892.

Hedges LV, Gurevitch J, Curtis PS (1999) The meta-analysis of response ratios in experimental ecology. Ecology, 80, 1150-1156.

Hopkin M (2006) Crops could make their own fertilizer. Nature News.

Ju XT, Xing GX, Chen XP et al. (2009) Reducing environmental risk by improving N management in intensive Chinese agricultural systems. Proceedings of the National Academy of Sciences of the United States of America, 106, 3041-3046.

Prasad R, Power JF (1995) Nitrification Inhibitors for Agriculture, Health, and the Environment. Advances in Agronomy, 54, 233-281.

Qiao C, Liu L, Hu S, Compton JE, Greaver TL, Li Q (2015) How inhibiting nitrification affects nitrogen cycle and reduces environmental impacts of anthropogenic nitrogen input. Global Change Biology, 21, 1249-1257.

This article is protected by copyright. All rights reserved. 
Rodgers GA, Wickramasinghe KN, Jenkinson DS (1985) Mineralization of Dicyandiamide, Labeled with N-15, in Acid Soils. Soil Biology \& Biochemistry, 17, 253-254.

Shaviv A (2005) Controlled release fertilizers. In: IFA International Workshop on Enhanced-Efficiency Fertilizers. pp Page, Frankfurt. International Fertilizer Industry Association Paris, France.

Smith P, Clark H, Dong H et al. (2014) Agriculture, forestry and other land use (AFOLU). In Climate Change 2014: Mitigation. Contribution of Working Group III to the Fifth Assessment Report of the Intergovernmental Panel on Climate Change (IPCC) (eds Edenhofer, O., Pichs-Madruga, R. P., Sokona, Y., Minx, J. C., Farahani, E., Kadner, S., Seyboth, K., Adler, A., Baum, I., Brunner, S., Eickemeier, P., Kriemann, B., Savolainen, J., Schlömer, S., von Stechow, C. V., Zwickel, T.) pp. 811-922. Cambridge University Press: Cambridge, UK.

Smith P, Martino D, Cai Z et al. (2007) Agriculture. In Climate change 2007: mitigation. Contribution of Working Group III to the Fourth Assessment Report of the Intergovernmental Panel on Climate Change (IPCC).(eds B Metz, OR Davidson, PR Bosch, R Dave, LA Meyer) pp. 497-540. Cambridge University Press: Cambridge, UK.

Sutton MA, Bleeker A, Howard C et al. (2013) Our nutrient world: the challenge to produce more food and energy with less pollution, NERC/Centre for Ecology \& Hydrology.

Sutton MA, Howard CM, Erisman JW et al. (2011a) The European nitrogen assessment: sources, effects and policy perspectives, Cambridge University Press.

Sutton MA, Oenema O, Erisman JW, Leip A, Van Grinsven H, Winiwarter W (2011b) Too much of a good thing. Nature, 472, 159-161.

Trenkel ME (1997) Controlled-release and stabilized fertilizers in agriculture, International fertilizer industry association Paris.

This article is protected by copyright. All rights reserved. 
Trenkel ME (2010) Slow-and controlled-release and stabilized fertilizers: An option for enhancing nutrient use efficiency in agriculture, IFA, International fertilizer industry association.

Van Grinsven HJM, Holland M, Jacobsen BH, Klimont Z, Sutton MA, Willems WJ (2013) Costs and Benefits of Nitrogen for Europe and Implications for Mitigation. Environmental Science \& Technology, 47, 3571-3579.

Vitousek PM, Naylor R, Crews T et al. (2009) Nutrient Imbalances in Agricultural Development. Science, 324, 1519-1520.

Xia LL, Lam SK, Chen DL, Wang JY, Tang Q, Yan XY (2017) Can knowledge-based N management produce more staple grain with lower greenhouse gas emission and reactive nitrogen pollution? A meta-analysis. Global Change Biology, 23, 1917-1925.

Zhang F, Cui Z, Chen X et al. (2012) Integrated Nutrient Management for Food Security and Environmental Quality in China. 116, 1-40.

Zhang X, Davidson EA, Mauzerall DL, Searchinger TD, Dumas P, Shen Y (2015) Managing nitrogen for sustainable development. Nature, 528, 51-59.

Fig. 1 Efficacy of polymer-coated fertilizers (PCF) on (a) $\mathrm{N}$ loss mitigation and (b) crop yield and NUE improvement in different cropping systems. Data shown as response ratios, where the value from conventional fertilizer was 1 . Mean effect and $95 \%$ CIs are shown. Numbers in parentheses indicate numbers of observations.

Fig. 2 Efficacy of nitrification inhibitors (NI) on (a) N loss mitigation and (b) crop yield and NUE improvement in different cropping systems. Baseline emissions from control/conventional treatments (all land use and other conditions combined) also shown. Data shown as response ratios, where the value from conventional fertilizer was 1 . Mean effect and 95\% CIs are shown. Numbers in parentheses indicate numbers of observations.

This article is protected by copyright. All rights reserved. 
Fig. 3 Efficacy of urease inhibitors (UI) on (a) $\mathrm{N}$ loss mitigation and (b) crop yield and NUE improvement in different cropping systems. Baseline emissions from control/conventional treatments (all land use and other conditions combined) also shown. Data shown as response ratios, where the value from conventional fertilizer was 1 . Mean effect and 95\% CIs are shown. Numbers in parentheses indicate numbers of observations.

Fig. 4 The efficacy of double inhibitors (DI) on (a) N loss mitigation and (b) crop yield and NUE improvement in different cropping systems. Baseline emissions from control/conventional treatments (all land use and other conditions combined) also shown. Data shown as response ratios, where the value from conventional fertilizer was 1. Mean effect and 95\% CIs are shown. Numbers in parentheses indicate numbers of observations.

Fig. 5 The $\mathrm{N}$ fluxes and yield change with enhanced-efficiency $\mathrm{N}$ fertilizers in different cropping systems, (a) grassland, (b) dryland, (c) paddy. Data for mean $\mathrm{N}$ application rate and the amount of $\mathrm{N}$ loss (sum of $\mathrm{N}$ lost as $\mathrm{N}_{2} \mathrm{O}+\mathrm{NH}_{3}+\mathrm{NO}_{3}^{-}, \mathrm{kg} \mathrm{N}^{-1}$ ) are shown at the top of the graph. The $\mathrm{NO}_{3}^{-}$ leaching loss with UI was not different from conventional treatment. Due to the limitation of data points, the effects on $\mathrm{NO}_{3}{ }^{-}$loss of PCF in grassland and DI in paddy systems (shown in slash pattern) are based on pooled studies of all systems.

Fig. 6 An illustration showing EEFs as an integral component of N-management strategies for increased productivity and decreased environmental losses with three distinct region-scenarios. (i) Regions featuring $\mathrm{N}$ deficit and low yield such as Sub-Saharan Africa need to boost $\mathrm{N}$ fertilizer use for improved food production; use of EEFs are unnecessary presently. (ii) For areas with excessive $\mathrm{N}$ input and low NUE such as China, eliminating fertilizer mismanagement (e.g. over-application) is a top priority. Implementation of knowledge-based $\mathrm{N}$ management practices coupled with EEFs offers a great potential for improving productivity and environmental outcomes. (iii) Regions with N more-or-less balanced such as North America could benefit from the use of EEFs, particularly if conventional $\mathrm{N}$ rate is downward adjusted. 


\section{Supplementary Information}

Supplementary Fig. 1 Global distribution of study sites included in the database for meta-analysis

Supplementary Fig. 2 The effect of polymer coated fertilizer (PCF) on nitrogen loss mitigation under different soil conditions

Supplementary Fig. 3 The effect of polymer coated fertilizer (PCF) on N loss mitigation under different irrigation regime

Supplementary Fig. 4 The effect of polymer coated fertilizer (PCF) on increasing crop yield and NUE under different climate conditions

Supplementary Fig. 5 The effect of polymer coated fertilizer (PCF) on increasing crop yield and NUE under different irrigation regime

Supplementary Fig. 6 The effect of nitrification inhibitor (NI) on N loss mitigation under different soil conditions

Supplementary Fig. 7 The effect of nitrification inhibitor (NI) on N loss mitigation under different irrigation regime

Supplementary Fig. 8 The effect of nitrification inhibitor (NI) on increasing crop yield and NUE under different climate conditions

Supplementary Fig. 9 The effect of nitrification inhibitor (NI) on increasing crop yield and NUE under different soil conditions

Supplementary Fig. 10 The effect of nitrification inhibitor (NI) on increasing crop yield and NUE under different irrigation regime

Supplementary Fig. 11 The effect of urease inhibitor (UI) on N loss mitigation under different annual rainfall conditions

Supplementary Fig. 12 The effect of urease inhibitor (UI) on N loss mitigation under different irrigation regime

This article is protected by copyright. All rights reserved. 
Supplementary Fig. 13 The effect of urease inhibitor (UI) on N loss mitigation under different annual soil conditions

Supplementary Fig. 14 The effect of urease inhibitor (UI) on increasing crop yield and NUE under different annual temperature conditions

Supplementary Fig. 15 The effect of urease inhibitor (UI) on increasing crop yield and NUE under different irrigation regime

Supplementary Fig. 16 The effect of double inhibitor (DI) on increasing yield and NUE under different annual rainfall conditions

Supplementary Fig. 17 The effect of double inhibitor (DI) on N loss mitigation under different irrigation regime

Supplementary Fig. 18 The effect of double inhibitor (DI) on increasing yield and NUE under different irrigation regime

Supplementary Fig. 19 The effect of double inhibitor (DI) on N loss mitigation under different annual soil conditions

Supplementary Fig. 20 The effect of double inhibitor (DI) on increasing crop yield and NUE under different soil conditions

Supplementary Fig. 21 The relationship of N loss reduction by EEFs with crop NUE increase

Supplementary Table 1 Numbers of studies and observations per type of enhanced-efficiency fertilizers and cropping systems in this database

Supplementary Table 2 Products per EEF type used in various studies

Supplementary Table 3 Methodologies of $\mathrm{N}$ loss measurements used in the selected studies

Supplementary Table 4 Mean $\mathrm{N}$ rate, emission factor and net $\mathrm{N}$ loss from three $\mathrm{N}$ loss forms from different land uses in this database

Supplementary Table 5 The integrated efficacy of PCF under various conditions

This article is protected by copyright. All rights reserved. 
Supplementary Table 6 The integrated efficacy of NI under various conditions

Supplementary Table 7 The integrated efficacy of UI under various conditions

Supplementary Table 8 The integrated efficacy of DI under various conditions

Supplementary Table 9 The between group heterogeneity (QB) of different variables for each EEF

Supplementary Table 10 Sensitivity analysis of integrated efficacy of EEF excluding outliers

Supplementary Table 11 The amounts of $\mathrm{N}_{2} \mathrm{O}, \mathrm{NH}_{3}, \mathrm{NO}_{3}{ }^{-}$leaching reduced by PCF, NI, UI, DI and reduction rate compared to conventional treatment

Supplementary Table 12 The response ratio (RR) of EEF on enhancing productivity and reducing $\mathrm{N}$ loss under different conditions in three cropping systems

Supplementary Table 13 The efficacy of EEF on productivity of maize, wheat and rice

Supplementary Table 14 Cost-benefit analysis of application of EEF in different crops and countries

Supplementary Table 15 The $\mathrm{N}$ loss reduction and uptake increase by EEF in different cropping system

Supplementary Table 16 Yield and NUE response to EEF under low and high N rate levels

Supplementary Table 17 Yield response to EEF under low and high $\mathrm{N}$ rate levels in different cropping system

Supplementary Data 1. Source references of all datasets used in this meta-analysis

This article is protected by copyright. All rights reserved. 


\section{Enhanced-efficiency fertilizers are not a panacea for resolving the nitrogen problem}

Tingyu Li ${ }^{1 *}$, Weifeng Zhang ${ }^{1 *}$, Jiao Yin ${ }^{1}$, David Chadwick ${ }^{2}$, David Norse ${ }^{3}$,

Yuelai Lu ${ }^{4}$, Xuejun Liu ${ }^{1}$, Xinping Chen ${ }^{1}$, Fusuo Zhang ${ }^{1}$, David Powlson ${ }^{5}$, and Zhengxia Dou ${ }^{6}$

Fig1a-b
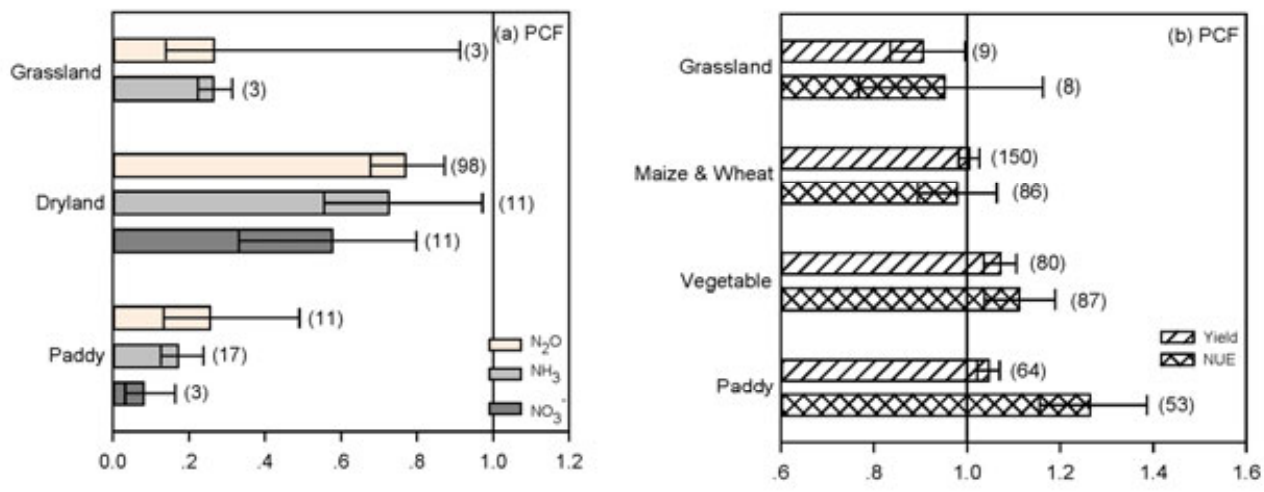

This article is protected by copyright. All rights reserved. 


\section{Fig2a-b}
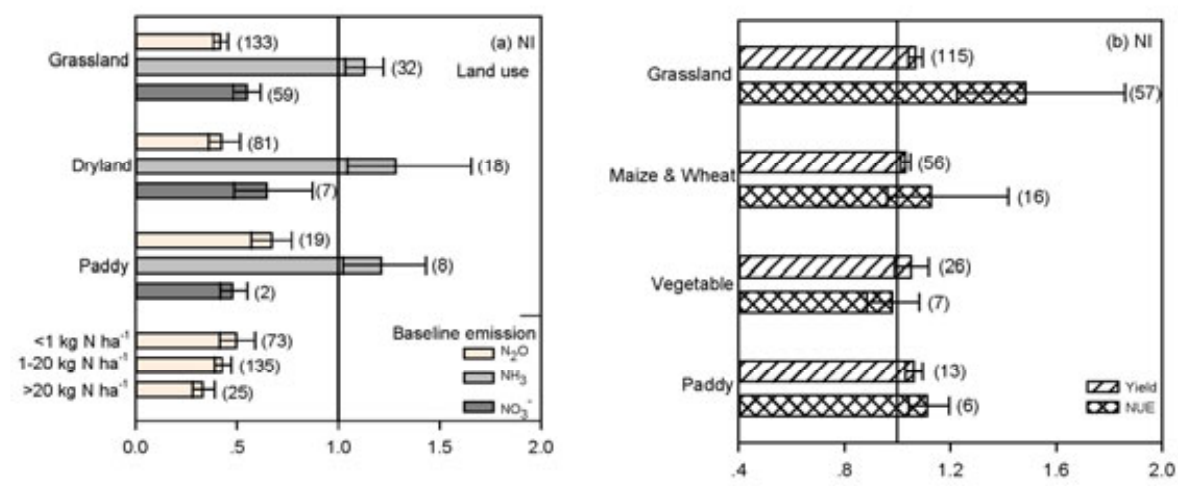

\section{Fig3a-b}
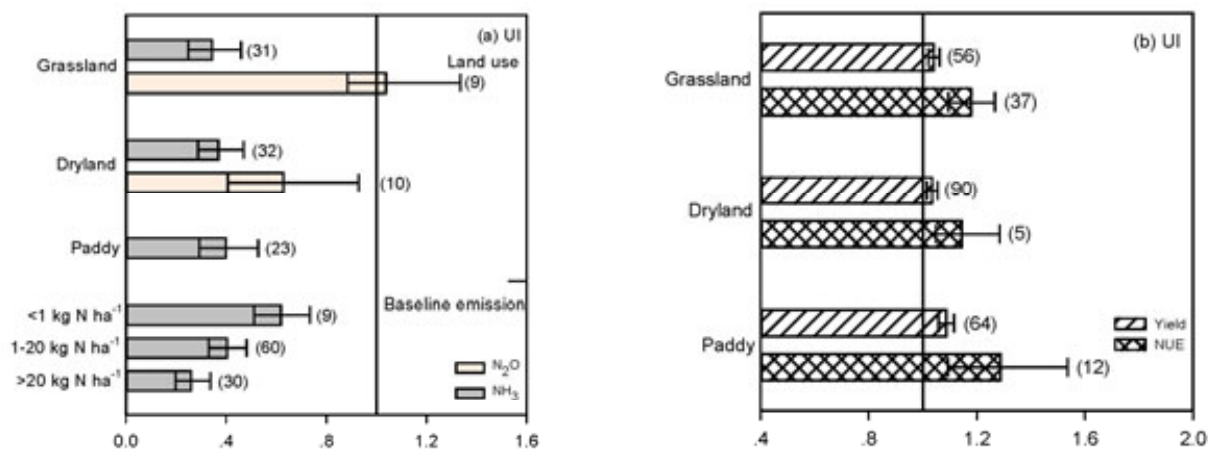

This article is protected by copyright. All rights reserved. 


\section{Fig4a-b}
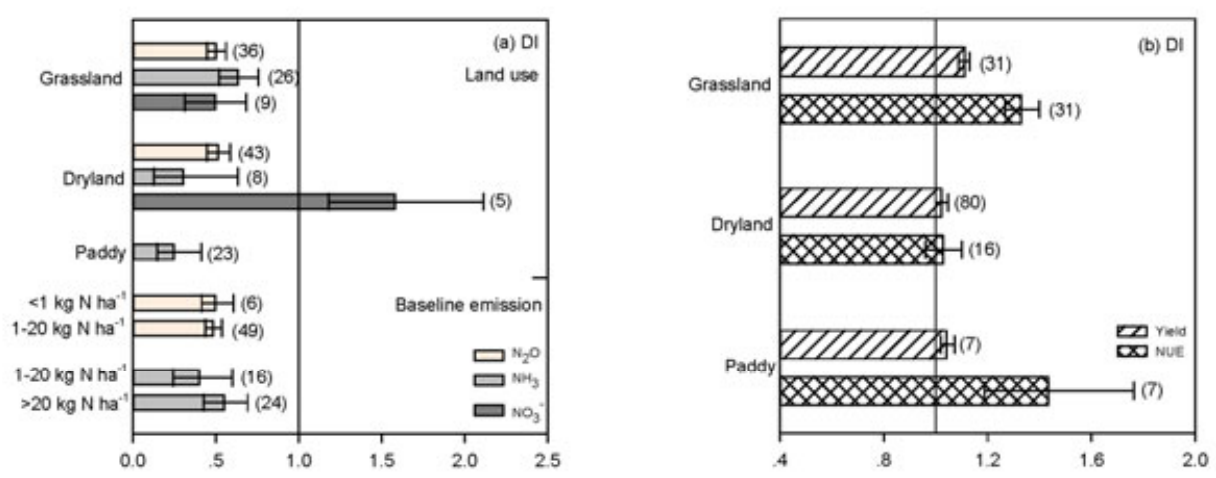

Fig5

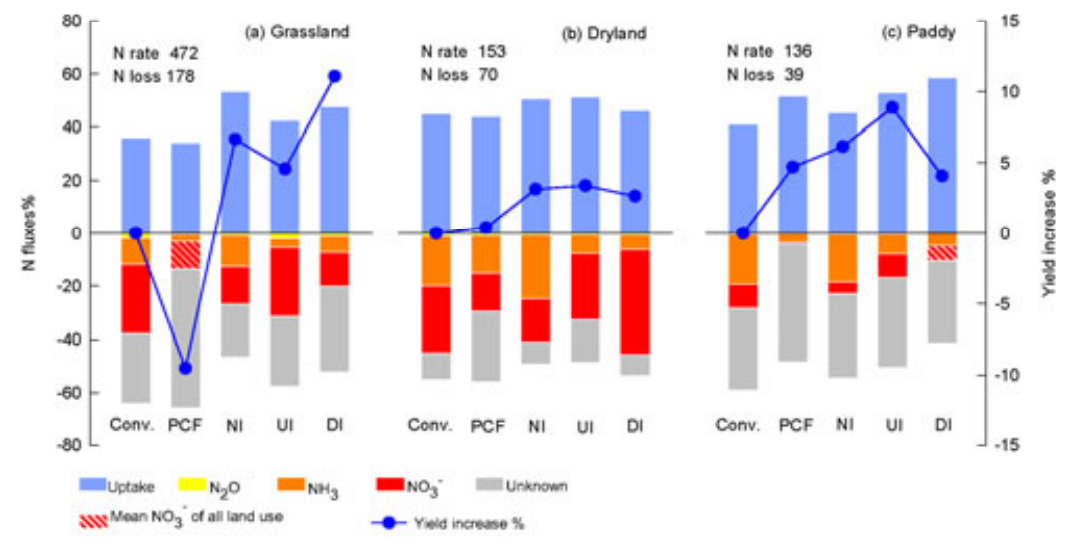

This article is protected by copyright. All rights reserved. 


\section{Fig6}
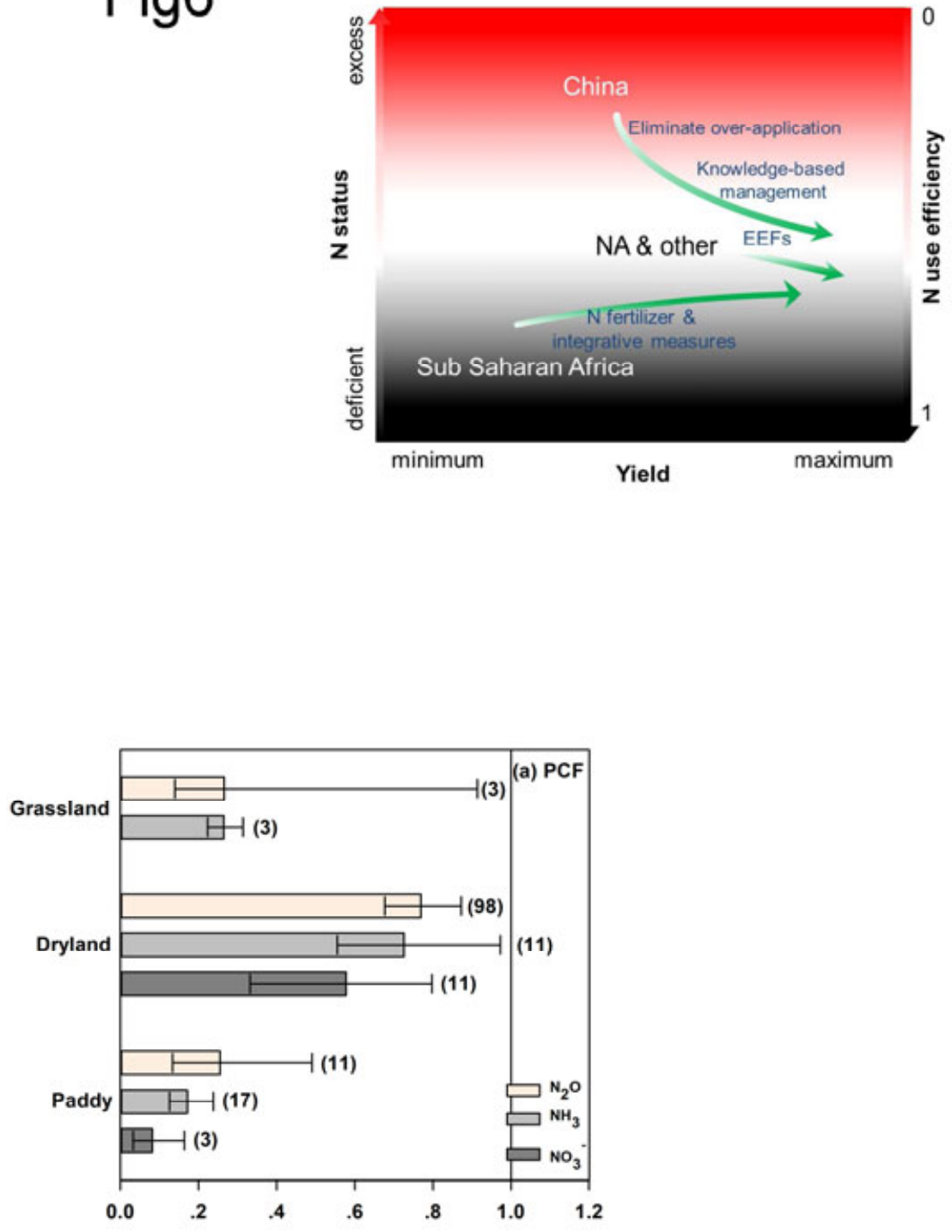

This article is protected by copyright. All rights reserved. 

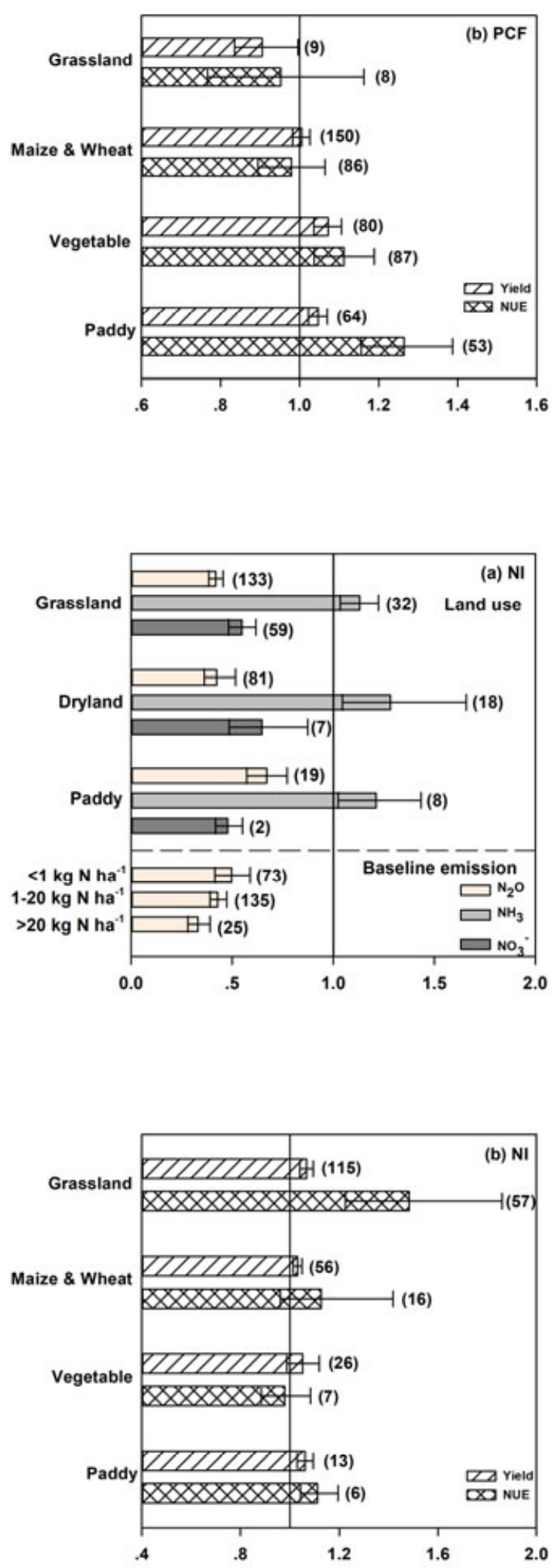

This article is protected by copyright. All rights reserved. 

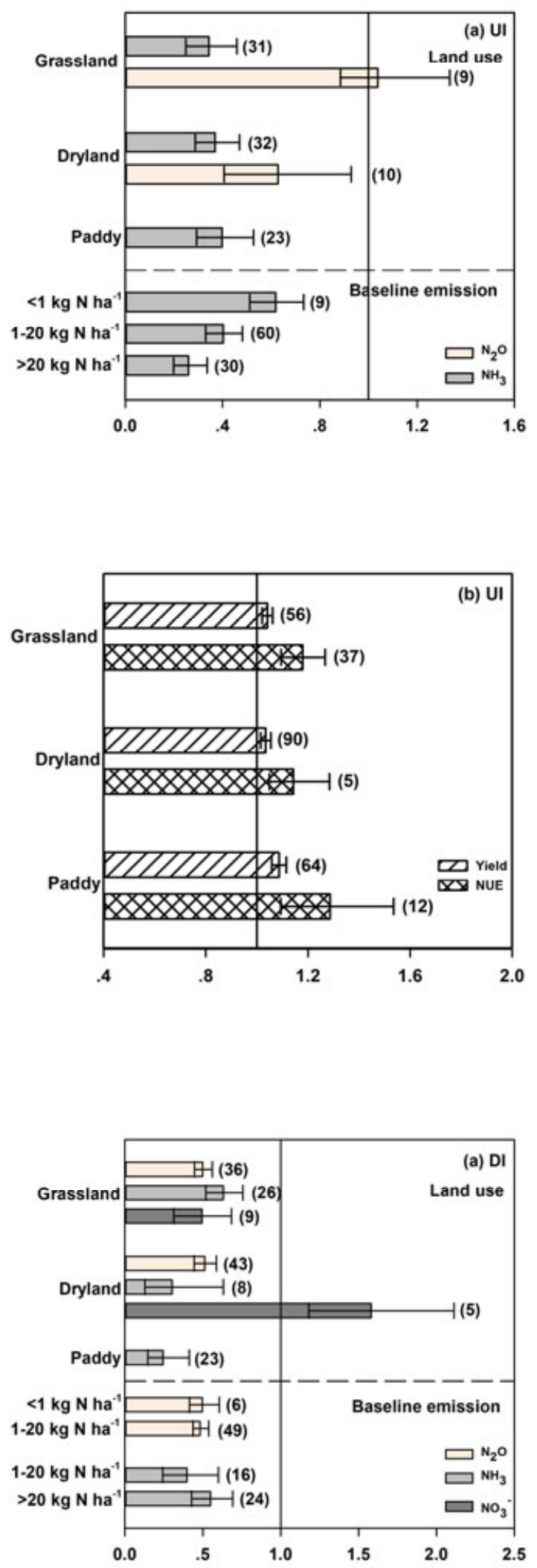

This article is protected by copyright. All rights reserved. 

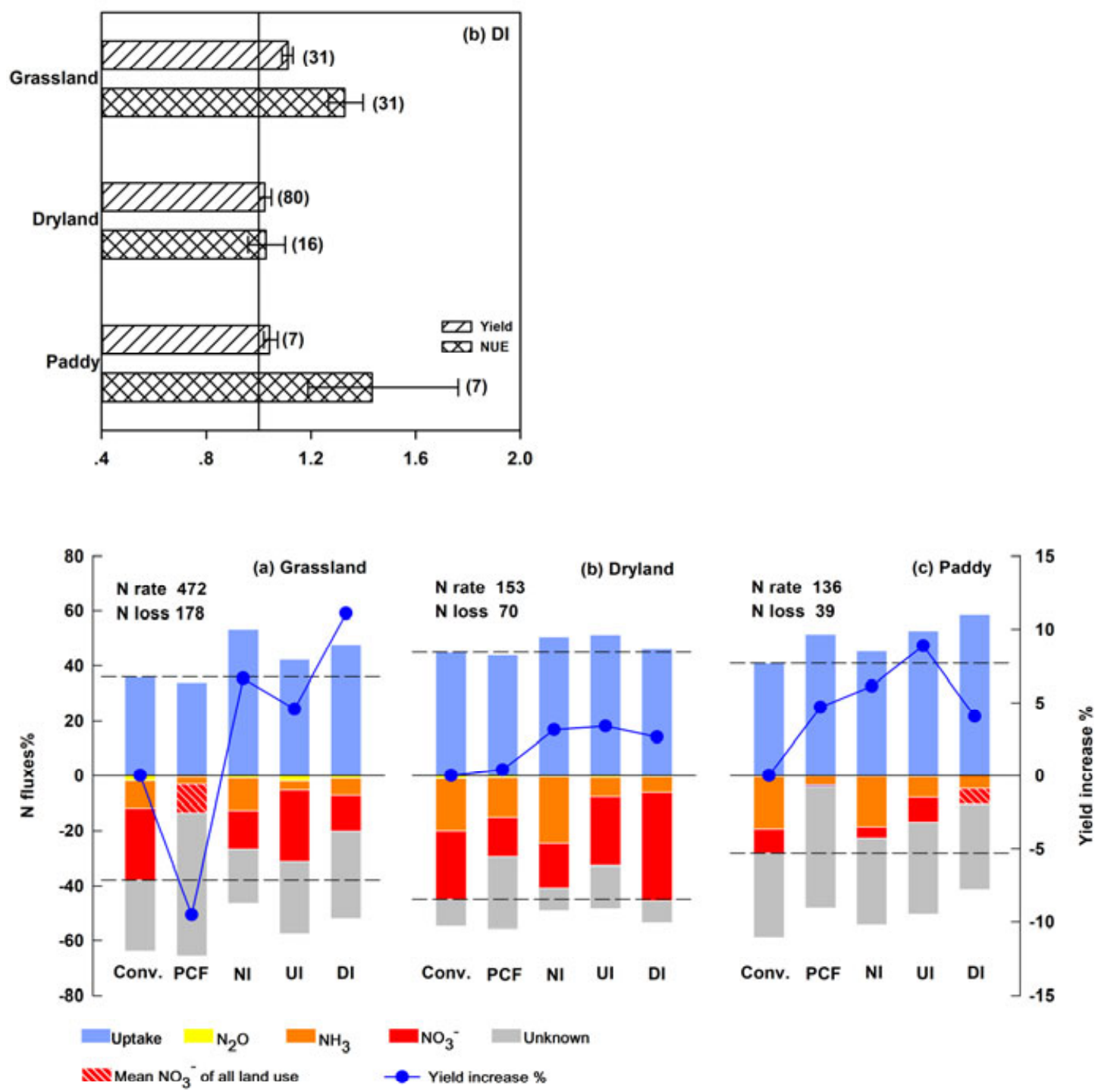

This article is protected by copyright. All rights reserved. 


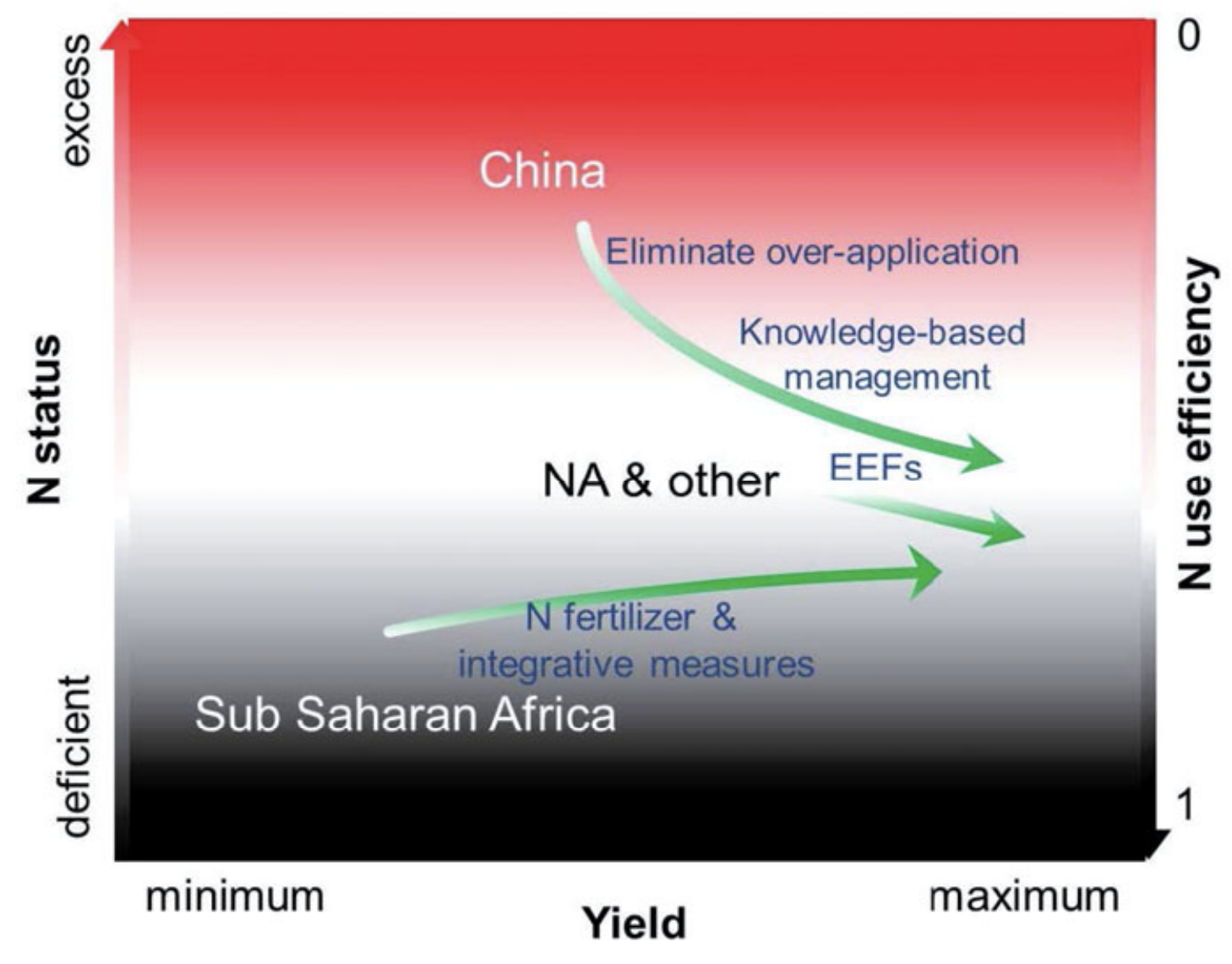

This article is protected by copyright. All rights reserved. 